\title{
Yacon (Smallanthus sonchifolius (Poepp. \& Endl.) H. Robinson) Improved Erythrocyte Resistance to Oxidative Stress in Streptozotocin-induced Diabetic Rats
}

\author{
Mariia Khokhla ${ }^{1, *}$, Olexandra Horbulinska ${ }^{1}$, Halina Hachkova ${ }^{1}$, Lidiya Mishchenko ${ }^{2}$, Olexandr Shulga ${ }^{3}$, \\ Rosa Vildanova ${ }^{3}$, Natalia Sybirna ${ }^{1}$ \\ ${ }^{1}$ Department of Biochemistry, Faculty of Biology, Ivan Franko National University of Lviv, Ukraine \\ ${ }^{2}$ Department of Virology, Institute of Biology, Taras Shevchenko National University of Kyiv, Ukraine \\ ${ }^{3}$ Department of Physical Chemistry of Combustible Minerals, L.M. Lytvynenko Institute of Physico-organic Chemistry and Coal \\ Chemistry NAS of Ukraine, Ukraine
}

Copyright (C) 2015 by authors, all rights reserved. Authors agree that this article remains permanently open access under the terms of the Creative Commons Attribution License 4.0 International License

\begin{abstract}
Yacon demonstrating prominent hypoglycemic action and having high content of biologically active compounds, is recognized for their ability to capture free radicals. This study is aimed to evaluate the influence of yacon leaves and root tubers water extracts and aqueous suspension of root tubers powder on rats' erythrocyte antioxidant defense system under the experimental diabetes mellitus type 1 . Healthy animals and animals with diabetes mellitus were treated with water extracts of yacon leaves and root tubers at dose 70 or $500 \mathrm{mg} / \mathrm{kg} /$ day and with aqueous suspension of root tubers powder at dose $500 \mathrm{mg} / \mathrm{kg} /$ day or the same suspension which was stabilized by biocomplex PS. Thiobarbituric acid reactive substances (TBARS) and protein carbonyl content (PCC), superoxide dismutase (SOD), catalase (CAT) and glutathione peroxidase (GPx) activity in erythrocytes lysates were measured. Water extracts of yacon leaves and root tubers and aqueous suspension of root tubers powder possess significant antioxidant effect, which was indicated by the decrease of TBARS and PCC and increase in SOD, CAT and GPx activity. Root tubers of yacon water extract at a dose of 500 $\mathrm{mg} / \mathrm{kg} / \mathrm{day}$ and aqueous suspension of root tubers powder stabilized by biocomplex PS possess he most pronounced antioxidant effect.
\end{abstract}

Keywords Yacon, Erythrocyte, Antioxidant State, Diabetes

\section{Introduction}

Type 1 diabetes mellitus (DM) is a chronic T-cellmediated autoimmune disease that results in the destruction of insulin-secreting $\beta$-cells. This pathology is associated with multiple metabolic disorders that are characterized by hyperglycemia and results from an absolute or relative deficiency in insulin secretion or action [1]. Hyperglycemia is often coupled with an increased state of oxidative stress originating from an increase production of reactive oxygen species (ROS) such as superoxide radical anion $\left(\mathrm{O}_{2}{ }^{-}\right)$, hydroxyl radical $\left(\mathrm{OH}^{*}\right)$, peroxyl radical $\left(\mathrm{ROO}^{\circ}\right)$ and hydrogen peroxide $\left(\mathrm{H}_{2} \mathrm{O}_{2}\right)$, and/or reactive nitrogen species such as nitric oxide radical $\left(\mathrm{NO}^{\circ}\right)$ and peroxynitrite $\left(\mathrm{ONOO}^{-}\right)$ [2]. Mechanisms that causes the increased oxidative stress in DM may include not only increased nonenzymatic glycosylation (glycation) and autoxidative glycosylation but also metabolic stress caused by the changes in energy metabolism, alterations in sorbitol pathway activity, changes in the level of inflammatory mediators and the status of antioxidant defense systems [3]. It is believed that oxidative stress plays a crucial role in the onset and progression of late-diabetic complications through activation of stress-sensitive intracellular signaling pathways and the formation of gene products that causes cellular damage [4].

Hyperglycemia is the most important factor of the onset and progress of diabetic complications. One of the most suitable models for the investigation of antioxidant defense system changes are red blood cells. Erythrocytes are continuously exposed to glucose in plasma during their circulatory life span. The glucose concentration in the erythrocyte cytosol is ensured by passive transport through GLUT1 (insulin-independent glucose transporter) and is close to that in the plasma and obviously increases under the conditions of hyperglycemia [5]. Red blood cells are also susceptible to ROS attacks because of their high polyunsaturated fatty acid content and their abundance of iron $\left(\mathrm{Fe}^{2+}\right)$-rich hemoglobin and molecular oxygen. Ionic $\mathrm{Fe}^{2+}$ acts as a catalyst in redox reactions and lipid 
peroxidation. In addition, erythrocytes often undergo membrane protein oxidation or carbonylation [6].

Free radicals generated by hyperglycemia are a plausible contributing factor of the increase of thiobarbituric acid reactive substances (TBARS) levels. In addition, increased glucose levels activate the polyol pathway. Aldose reductase, the first and rate-limiting enzyme in the pathway, reduces glucose to sorbitol using NADPH as a cofactor. Then, sorbitol is reduced to fructose by sorbitol dehydrogenase which uses $\mathrm{NAD}^{+}$as a cofactor. Redox imbalance following the depletion of NADPH and $\mathrm{NAD}^{+}$further contributes to cell damage. A decrease in NADPH levels can lead to a deficiency of reduced glutathione (GSH), which could induce or worsen intracellular oxidative stress [7].

One of the plants that has recently been intensively studied is yacon (Smallanthus sonchifolius (Poepp. \& Endl.) H. Robinson; Asteraceae). Several authors have demonstrated distinct hypoglycemic action of water extract of yacon leaves and tuberous root $[8,9,10,11]$.

There are several possibilities of the mechanisms by which the plant reduces blood glucose concentration: reduction of the intestinal absorption of glucose, increase in glucose uptake by tissues and organs, increased release of insulin through stimulating the $\beta$-pancreatic cells, resistance to the hormones that increases the rate of glucose release, increase of the number and sensitivity of the insulin receptors and the decrease of glycogen degradation rate, among others [12].

The benefit of yacon as the basis for creating hypoglycemic drugs is that it has high content of biologically active compounds, recognized for their ability to capture free radicals. It was shown that hot water extract of the aerial part of yacon demonstrates powerful free radical-scavenging activity and inhibitory effects on lipid peroxidation in rat brain homogenate [13]. Active components extracted from S. sonchifolius leaves showed the great antioxidant activity in 1,1-diphenyl-2-picrylhydrazyl and xanthine/xanthine oxidase superoxide radical scavenging tests, they inhibited the lipoperoxidation of rat liver subcellular membranes and protected rat hepatocytes against oxidative injury [14, 15, 16]. Similar effect was demonstrated by the compounds from yacon tuberous root [17]. Moreover yacon leaves and tuber extracts inhibited the production of NO in macrophage in vitro $[9,18]$.

Researches that are mentioned above and dedicated to screening of yacons antioxidant activity were conducted in vitro, and do not take into consideration some aspects of the potential antioxidant bioavailability among which there are their uptake and metabolism that are crucial to the effectiveness of the antioxidant in vivo.

Therefore, this study is aimed to evaluate the influence of water extracts of leaves and root tubers of yacon and water suspension of root tubers powder on rats' erythrocyte antioxidant defense system under the experimental diabetes mellitus type 1 that was induced by intraabdominal injection of streptozotocin (STZ), as bolus injection.

\section{Material and Methods}

\subsection{Preparation of Water Extracts}

For this research yacons plant material that was introduced in Kiev region (Ukraine) was used. Leaves and root tubers of yacon were infusioned in water (ratio 1:10) in two following stages: 15 minutes at $100^{\circ} \mathrm{C}$ and 45 minutes at $20^{\circ} \mathrm{C}$. The raw water extracts were filtered and evaporated under reduced pressure using a rotary evaporator LABOROTA 4001 (Heidolph, Germany) at a temperature of $60-65^{\circ} \mathrm{C}$. For the research water solutions of evaporated extracts, by which control animals and animals with diabetes mellitus were treated orally for 2 weeks, were used.

\subsection{Preparation of Aqueous Suspension of Root Tubers Powder}

The suspension of root tubers was obtained by mixing homogeneous powdered mass of root tubers with water (500 $\mathrm{mg}$ of powder per $\mathrm{kg}$ of body weight in $1 \mathrm{ml}$ of water per 1 rat). In order to improve stability and bioavailability of bioactive agents the suspension of root tubers was stabilized by biocomplex PS, added at a concentration of $0.1 \mathrm{ml}$ per 1 $\mathrm{ml}$ of suspension. Surface-active biocomplex PS was isolated from the supernatant culture fluid of the Pseudomonas sp strain. The suspension of root tubers and its stabilized form has been injected for 2 weeks per os to animals in control group and animals with diabetes mellitus.

\subsection{Experimental Animals}

The experiments were conducted using male Wistar rats weighing 150 to $220 \mathrm{~g}$. The animals were maintained in controlled temperature $\left( \pm 22^{\circ} \mathrm{C}\right)$ and a 12-hour dark-light cycle, with balanced food and free access to water. Experiments were carried out according to the "General ethical principles of experiments on animals", adopted at the

I National Congress on Bioethics (Kyiv, 2001).

Animals were divided into following groups $(n=$ 6/group):

1. control animals $(\mathbf{C})$;

2. control animals that were treated orally with water extract of yacon leaves at doses $70 \mathrm{mg} / \mathrm{kg} /$ day $(\mathbf{C}+$ $\left.\mathbf{E}_{\mathbf{L}}{ }^{\mathbf{7 0}}\right)$ and $500 \mathrm{mg} / \mathrm{kg} / \mathrm{day}\left(\mathbf{C}+\mathbf{E}_{\mathbf{L}}{ }^{\mathbf{5 0 0}}\right)$;

3. control animals that were treated orally with extract of yacon root tubers at doses $70 \mathrm{mg} / \mathrm{kg} /$ day $\left(\mathbf{C}+\mathbf{E}_{\mathbf{R}}{ }^{\mathbf{7 0}}\right)$ and $500 \mathrm{mg} / \mathrm{kg} /$ day $\left(\mathbf{C}+\mathbf{E}_{\mathbf{R}}{ }^{\mathbf{5 0 0}}\right)$;

4. control animals that were treated orally with water suspension of root tubers powder $(\mathbf{C}+\mathbf{S})$ and with water suspension of root tubers powder stabilized by biocomplex PS $\left(\mathbf{C}+\mathbf{S}^{\mathbf{P S}}\right)$;

5. animals with experimental diabetes mellitus (DM);

6. animals with diabetes that were treated orally with yacon leaves extract at doses $70 \mathrm{mg} / \mathrm{kg} /$ day $(\mathbf{D M}+$ $\left.\mathbf{E}_{\mathbf{L}}{ }^{\mathbf{7 0}}\right)$ and $500 \mathrm{mg} / \mathrm{kg} /$ day $\left(\mathbf{D M}+\mathbf{E}_{\mathbf{L}}{ }^{\mathbf{5 0 0}}\right)$

7. animals with diabetes that were treated orally with yacon root tubers extract at doses $70 \mathrm{mg} / \mathrm{kg} /$ day 
$\left(\mathbf{D M}+\mathbf{E}_{\mathbf{R}}{ }^{\mathbf{7 0}}\right)$ and $500 \mathrm{mg} / \mathrm{kg} /$ day $\left(\mathbf{D M}+\mathbf{E}_{\mathbf{R}}{ }^{\mathbf{5 0 0}}\right)$

8. animals with diabetes that were treated orally with aqueous suspension of root tubers powder $(\mathbf{D M}+\mathbf{S})$ and with aqueous suspension of root tubers powder stabilized by biocomplex PS $\left(\mathbf{D M}+\mathbf{S}^{\mathbf{P S}}\right)$

\subsection{Induction of Diabetes}

Following an overnight starvation, diabetes was induced by intraabdominal injection of STZ (Sigma, USA) (freshly dissolved in $10 \mathrm{mM}$ citrate buffer ( $\mathrm{pH}$ 5.5) before use) at a dose of $0,055 \mathrm{~g} / \mathrm{kg}$ body weight. The fasting blood glucose level was measured after 3 days to assess the development of diabetes mellitus. In the $\mathrm{DM}+\mathrm{E}_{\mathrm{L}}{ }^{500}, \mathrm{DM}+\mathrm{E}_{\mathrm{L}}{ }^{70}, \mathrm{DM}+\mathrm{E}_{\mathrm{R}}{ }^{70}$, $\mathrm{DM}+\mathrm{E}_{\mathrm{R}}{ }^{500}, \mathrm{DM}+\mathrm{S}, \mathrm{DM}+\mathrm{S}^{\mathrm{PS}}$ groups the studied extracts and suspension started to be administered on the 14 day after induction of diabetes.

\subsection{Collection of Blood}

At the end of the experimental period, the rats were starved for $15 \mathrm{~h}$ and then anesthetized using deep ether anesthesia method. Whole blood was collected and immediately transferred to heparinized tubes.

\subsection{Preparation of Erythrocyte Lysate}

Erythrocytes were separated from plasma by centrifugation at $1700 \mathrm{~g}$ for $10 \mathrm{~min}$. Red blood cells were washed three or four times with an isotonic solution of $\mathrm{NaCl}$ $(0.9 \%)$ until a colorless supernatant was observed. To obtain erythrocyte hemolysate, $500 \mu \mathrm{L}$ of erythrocyte was crushed by addition of three volumes of cold redistilled water. Afterwards it was centrifuged twice to remove all of the cell membranes: first for 10 minutes in the tube centrifuge at $3500 \mathrm{rpm}$ at $4^{\circ} \mathrm{C}$, then in an Eppendorf centrifuge at 7800 rpm for 5 minutes at $4^{\circ} \mathrm{C}$. Clear supernatant was obtained as hemolysate.

\subsection{Biochemical Analysis}

The level of glucose in plasma was determined by glucose oxidase method using a commercially available kit (Filisit diagnostics, Ukraine). The level of glucose in plasma was determined as a routine procedure with the purpose of accurate testing of rats belonging to groups of diabetic animals. These results are not shown in this article. Protein concentration was determined by Lowry method [19].

\subsection{Estimation of Thiobarbituric Acid Reactive Substances (TBARS) and Protein Carbonyl Content (PCC) in Erythrocytes Lysates}

Evaluation of oxidative damage of various cell components was performed by the content of the products of oxidative damage of proteins (PCC) and lipids (TBARS). The content of protein carbonyl groups was determined by reaction of aldehyde and ketone groups of aliphatic amino acid with 2,4-dinitrophenylhydrazine reagent to form protein-conjugated hydrazones with characteristic absorption spectrum at $360 \mathrm{~nm}$ [20]. The results were expressed as r.u. (relative units)/g of protein. TBARS was determined using the reaction of formation of a red complex of malonaldehyde: TBA (1:2) with an absorbance maximum of $532 \mathrm{~nm}$ [21]. The results were expressed as a percentage in comparison with a control sample that was taken as $100 \%$.

\subsection{Determination of Antioxidant Enzymes Activity in Erythrocyte Lysate}

Superoxide dismutase (SOD) activity was determined by a method which is based on restoring white-yellow nitro blue tetrazolium dye to dark purple formazan [22]. The results were expressed as $\mathrm{U}$ (unit)/ $\mathrm{mg}$ of protein.

The activity of catalase (CAT) was calculated by the intensity of color complex formed by the interaction of ammonium molybdate with $\mathrm{H}_{2} \mathrm{O}_{2}$ [23]. The level of CAT was expressed in terms of nmoles $\mathrm{H}_{2} \mathrm{O}_{2}$ consumed/min per mg of protein.

Activity of glutathione peroxidase (GPx) was determined by the speed of glutathione oxidation in the presence of tert-butyl hydroperoxide [24]. The level of GPx was expressed in terms of $\mu$ moles $\mathrm{G}-\mathrm{SH}$ consumed/min per mg of protein.

\subsection{Statistical Analysis}

Data are expressed as mean \pm S.E.M. Differences among experimental groups were determined by ANOVA (analysis of variance), and the significance of between-group differences assessed by Student-Newman-Keul's multiple range test. Significance was defined at $\mathrm{P} \leq 0.05$.

\section{Results}

Experimental diabetes mellitus is accompanied by increase of TBARS by $164 \%$ compared with erythrocytes lysates of the control group. Also the $77 \%$ increase of protein carbonyl content compared to control group was established (Figures 1). The increase in the erythrocytes TBARS and carbonyl level is related to the oxidative damage of lipid and protein by elevated oxygen free radicals in the diabetic group. Those indirectly suggest an increased production of oxygen free radicals in diabetic rats.

Leaves and root tubers water extracts and aqueous suspensions of root tubers powder cause the reduction of TBARS in control animals respectively by $44 \%\left(\mathrm{C}+\mathrm{E}_{\mathrm{L}}{ }^{70}\right)$, $47 \%\left(\mathrm{C}+\mathrm{E}_{\mathrm{L}}{ }^{500}\right), 60 \%\left(\mathrm{C}+\mathrm{E}_{\mathrm{R}}{ }^{70}\right), 37 \%\left(\mathrm{C}+\mathrm{E}_{\mathrm{R}}{ }^{500}\right), 56 \%$ $(\mathrm{C}+\mathrm{S}), 39 \%\left(\mathrm{C}+\mathrm{S}^{\mathrm{PS}}\right)$ and in animals with diabetes by $75 \%\left(\mathrm{DM}+\mathrm{E}_{\mathrm{L}}{ }^{70}\right), 86 \%\left(\mathrm{DM}+\mathrm{E}_{\mathrm{L}}^{500}\right), 83 \%\left(\mathrm{DM}+\mathrm{E}_{\mathrm{R}}{ }^{70}\right)$, $58 \%\left(\mathrm{DM}+\mathrm{E}_{\mathrm{R}}^{500}\right), 81 \%(\mathrm{DM}+\mathrm{S}), 83 \%\left(\mathrm{DM}+\mathrm{S}^{\mathrm{PS}}\right)$. Water extracts and aqueous suspensions cause PCC reduction on the condition of diabetes mellitus: $43 \%$ (DM $\left.+\mathrm{E}_{\mathrm{L}}{ }^{70}\right), 33 \%\left(\mathrm{DM}+\mathrm{E}_{\mathrm{L}}^{500}\right), 38 \%\left(\mathrm{DM}+\mathrm{E}_{\mathrm{R}}{ }^{70}\right), 29 \%(\mathrm{DM}$ $\left.+\mathrm{E}_{\mathrm{R}}^{500}\right), 34 \%(\mathrm{DM}+\mathrm{S}), 45 \%\left(\mathrm{DM}+\mathrm{S}^{\mathrm{PS}}\right)$ (Figures 1). 


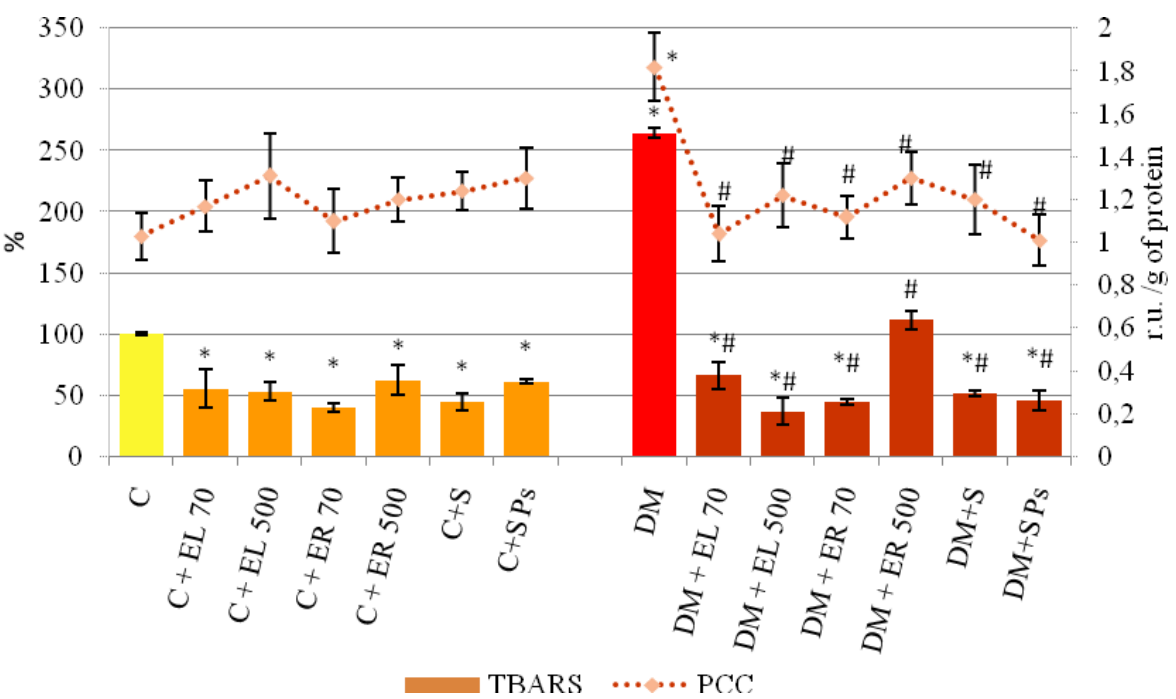

$* \mathrm{P}<0.05$ compared with controls.

$\# \mathrm{P}<0.05$ compared with diabetic rats without water extracts or aqueous suspension consumption.

Figure 1. Effect of yacon water extracts and aqueous suspension of root tubers powder on thiobarbituric acid reactive substances (TBARS) and protein carbonyl content (PCC) on healthy and diabetic rats.

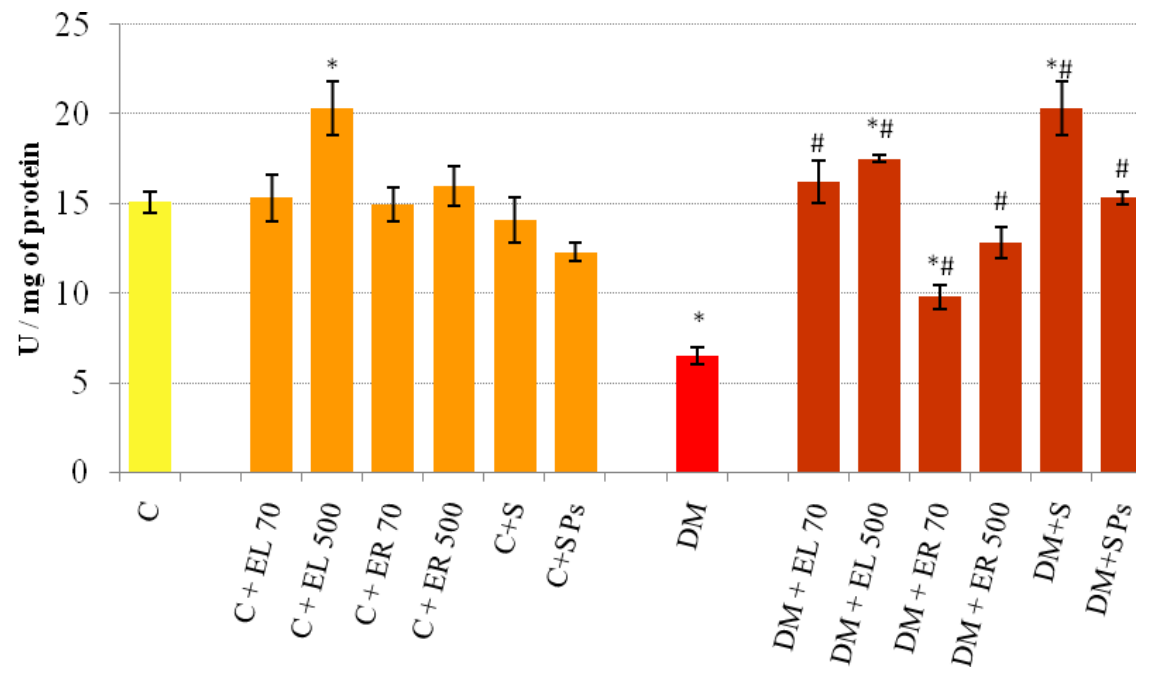

A

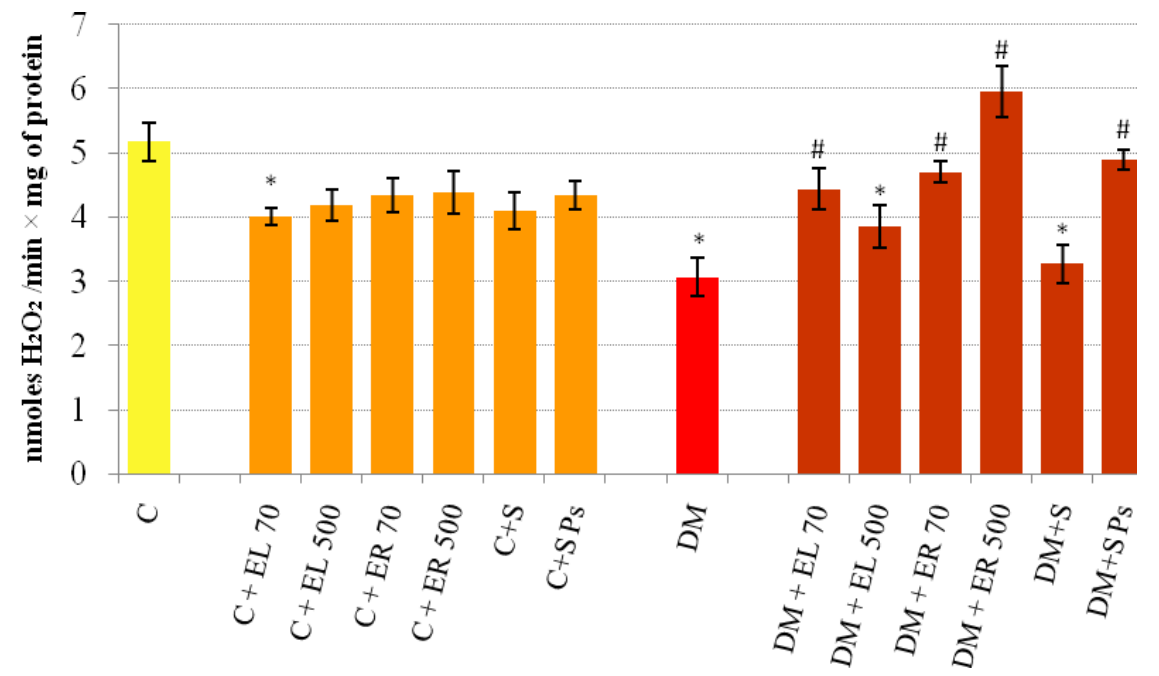




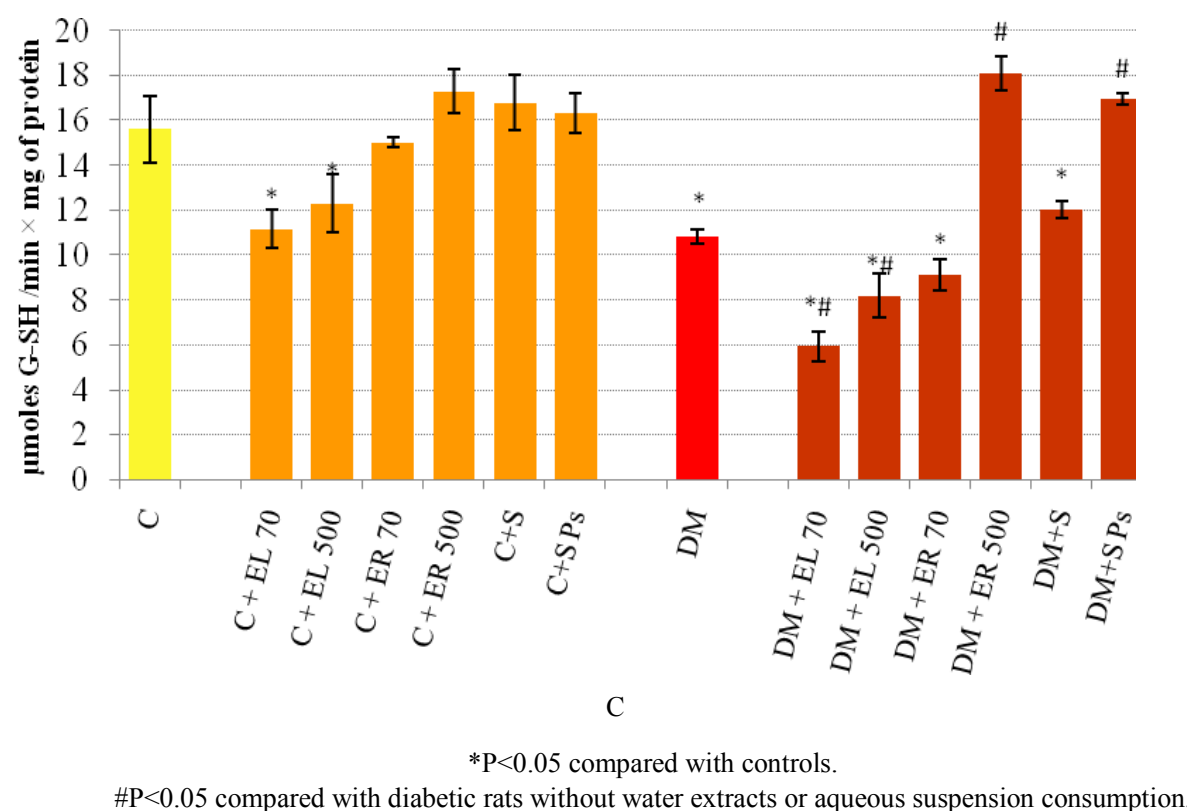

Figure 2. Effect of yacon water extracts and aqueous suspensions of root tubers powder on superoxide dismutase (A), catalase (B) and glutathione peroxidase (C) activity on healthy and diabetic rats.

Altered erythrocyte antioxidant enzyme activities were shown in a group of diabetic animals. SOD activity was reduced to $6,50 \pm 0,50$ compared to $15,10 \pm 0,60$ in control group (Figures 2A). GPx activity were diminished to $10,84 \pm 0,31$ in case of diabetes, while in control group activity of this enzyme were 15,62 $\pm 1,48$ (Figures 2C). Similar changes were observed with the catalase activity, in particular CAT activity in animals with diabetes mellitus was $3,06 \pm 0,30$ compared to $5,18 \pm 0,31$ in healthy animals (Figures 2B).

Application of yacon leaf extract at a dose of 70 and 500 $\mathrm{mg} / \mathrm{kg}$ in condition of diabetes causes increased activity of SOD respectively to $149 \%$ and $169 \%$, but in control animals the increase by $35 \%$ of the investigated enzyme activity was found only while the use of extract at a dose of $500 \mathrm{mg} / \mathrm{kg}$ (Figure 2A). In diabetic conditions investigated extract at a dose of $70 \mathrm{mg} / \mathrm{kg}$ also causes increased CAT activity by $45 \%$, while the extract at the dose of $500 \mathrm{mg} / \mathrm{kg}$ causes increased in CAT activity by $26 \%$ compared to animals that did not consume the extract (Figure 2B). These extract have opposite effect on the GPx activity, significant reduction of the enzyme activity was shown even in comparison with diabetes (Figure 2C).

We have found less pronounced effect while using water extracts of yacon root tubers at a dose of 70 and $500 \mathrm{mg} / \mathrm{kg}$, in particular SOD activity has grown to $51 \%$ and $97 \%$ in comparison with DM (Figure 2A). Water extracts of root tubers at a dose of $70 \mathrm{mg} / \mathrm{kg}$ lead to the increased activity of catalase at $54 \%$ but do not affect the activity of GPx, whereas at higher dose the studied extract causes the increase of CAT and GPx activity respectively at $94 \%$ and at $67 \%$ (Figure 2B, 2C).

Aqueous suspension of root tubers powder caused $213 \%$ increased activity of SOD in animals with diabetes (Figure
2A), but has shown no effect on CAT and GPx activity in control and diabetic animals (Figure 2B, 2C).

Aqueous suspension of root tubers powder stabilized by biocomplex PS in animals with diabetes mellitus caused the increase of SOD activity by $136 \%$, while CAT and GPx activity grew by $60 \%$ and $57 \%$, respectively (Figure $2 \mathrm{~A}$, $2 \mathrm{~B}, 2 \mathrm{C})$.

\section{Discussion}

The evidence has shown the importance of by-products in lipid peroxidation process such as reactive aldehydes in the occurrence of many oxidatively modified proteins. Increasing lipid peroxidation is an autocatalytic chain reaction and many of its products, including hydroxynonenal and hydroxyhexanal, are themselves very powerful damagers of proteins [25]. Indeed, we have established the increase of protein carbonyl content in erythrocytes lysates compared with control group (Figures 1). Carbonyl groups (aldehydes and ketones) are produced on protein side chains (especially of Pro, Arg, Lys, and Thr) while being oxidised. In addition, carbonyl groups may be introduced into proteins by secondary reaction of the nucleophilic side chains of Cys, His, and Lys residues, with aldehydes (4-hydroxy-2-nonenal, malondialdehyde, 2-propenal [acrolein]) produced during lipid peroxidation or with reactive carbonyl derivatives (ketoamines, ketoaldehydes, deoxyosones). Such derivatives have been generated as a consequence of the reaction of reducing sugars, or their oxidation products with lysine residues of proteins (glycation and glycoxidation reactions). All this reactions eventually lead to the formation of the advanced glycation/lipoxidation end products (AGEs/ALEs) [25]. The introduction of carbonyl groups into proteins 
causes alterations in protein conformation leading to increased aggregation, fragmentation, distortion of secondary and tertiary structures, and susceptibility to proteolysis, and decrease of normal function [26].

To counteract those damaging free radical species, system of highly effective antioxidants that include SOD, CAT and GPx have been developed. Superoxide dismutase remove superoxide radical by accelerating its conversion to hydrogen peroxide $\left(\mathrm{H}_{2} \mathrm{O}_{2}\right)$ while glutathione peroxidase detoxifies $\mathrm{H}_{2} \mathrm{O}_{2}$ and lipid peroxides. CAT acts in the decomposition of hydrogen peroxide $\left(\mathrm{H}_{2} \mathrm{O}_{2}\right)$ to water and oxygen [4]. These enzymes can also be a potential target for modification by elevated level of free radicals and, to our opinion, it was interesting to investigate the changes in activity of antioxidants enzymes in condition of diabetes.

Erythrocyte antioxidant enzyme activities were altered in group of diabetic animals (Figures 2). The decrease in SOD activity in the hyperglycemic rats could occur due to oxidative stress induced by inactivation of enzyme. Increased $\mathrm{H}_{2} \mathrm{O}_{2}$ concentration, for example, is known to inactivate SOD. Glycosylation of SOD and/or loss of $\mathrm{Cu}^{2+}$, a cofactor required for SOD activity, can also reduce SOD activity [4]. Also, the decrease in the activities of protective antioxidant enzymes in erythrocytes of diabetic animals can occur due to increased utilization of these enzymes for scavenging free radicals or due non-enzymatic glycation of the enzyme protein [27]. Low antioxidant enzyme activities render cells vulnerable to oxygen radical attack, and thus increase the diabetic complications [28].

Water extracts of leaves and root tubers and aqueous suspensions of root tubers powder cause the reduction of TBARS in control animals and in animals with diabetes (Figures 1). It should be noted that such reduction does not depend on the dose of extracts or the form of suspension. A same inhibitory effect on lipid peroxidating of hot water extract was found in rat brain homogenate [13]. Similar changes were found in the study of the influence of water extracts and aqueous suspensions on PCC, but reducing the studied parameters were shown only on the condition of diabetes mellitus (Figures 1).

Such effects of studied extracts and suspensions can be associated with the ability of biologically active substances of yacon, to cause the increase of glucose-6-phosphate dehydrogenase expression. NADPH produced by glucose-6-phosphate dehydrogenase participates in both the production of reactive oxygen species, such as superoxide anions and nitric oxide, and in the elimination of these radicals via glutathione peroxidase. Increased expression of glucose-6-phosphate dehydrogenase has been associated with increased glutathione levels and resistance to oxidative stress. Glutathione plays an important role in the protection of erythrocytes from oxidative modification of proteins, because its SH-group oxidized easier than the proteins SH-group, protecting the last from oxidative modification [29].

Multidirectional effects of yacon leaf extract (Figure 2) on the antioxidant enzyme activities may be related to competitive relation of enzyme to the concentration of the common substrate. The content of hydrogen peroxide increases under the conditions of SOD activity growth. At high concentrations hydrogen peroxide is inactivated by CAT, the activity of which actually increases in diabetic animals treated with extracts of leaves.

The antioxidant effect of leaf extract may be caused by the presence of phenolic compounds like caffeic acid and its derivatives (2,3,5-tricaffeoylaltraric acid, 3, 5-dicaffeoylquinic acid, 1,5-di-O-caffeoylquinic acid) chlorogenic acid, protocatechuic acid and ferulic acid, which show antioxidant and free radical scavenging activity $[12,13,14,15,30,31]$.

It has been shown previously that chlorogenic and caffeic acid to scavenge $\mathrm{N}_{2} \mathrm{O}_{3}$, organic free radicals, $\mathrm{HOCl}, \mathrm{O}_{2}{ }^{-}, \cdot \mathrm{OH}$, $\mathrm{ONOO}^{-}$and peroxy radical effectively. Unlike most antioxidants, products of chlorogenic and caffeic acid formed by reaction with free radicals are then rapidly broken down to the products which are unable to generate any free radicals. This is the beneficial nature for antioxidant, because other antioxidants are not necessary for the reduction of one-electron oxidation products of chlorogenic and caffeic acid. Although chlorogenic and caffeic acid cannot react directly with $\mathrm{H}_{2} \mathrm{O}_{2}, \mathrm{H}_{2} \mathrm{O}_{2}$ can be scavenged by those quinones and by peroxidases plus these phenolics. The destruction of $\mathrm{H}_{2} \mathrm{O}_{2}$ is stimulated after adding such reducing agent, as ascorbate, to the peroxidase / chlorogenic acid / $\mathrm{H}_{2} \mathrm{O}_{2}$ system. This may be related to the ability of reducing agent to reduce o-quinone derivatives. Phenolic compounds act as the primary reducing agent of $\mathrm{H}_{2} \mathrm{O}_{2}$ and can acts as the secondary and ultimate reductant. Thus, chlorogenic and related compounds can overcome deleterious effects of reactive species of oxygen and nitrogen, and organic free radicals in vivo [32].

It was also found that leaves of yacon are rich in flavonoids: 5, 7-dihydroxy-4'-methoxyflavonol, 5, 7, 3'-trihydroxy-4'-methoxyflavonol, 5-hydroxy-4'-methoxy7-O-glycosilflavone and 7,4'-dihydroxy-3,5'-dimethoxyflav one, that demonstrate antioxidant activity similar to rutin, quercetin and vitamin C [33]. Flavonoids can dampen transition metal enhancement of oxidation by donating an $\mathrm{H}^{*}$ to them, rendering them less proxidative. In addition, flavones and some flavanones can preferentially bind metals at the 5-hydroxyl and 4-oxo groups [34].

We have found less distinct effect on SOD activity using water extracts of yacon root tubers. Higher dose of extracts of root tubers causes significant increases of CAT and GPx activity. Aqueous suspension of root tubers powder stabilized by biocomplex PS has the best effect among all studied herbal remedies under the conditions of experimental DM (Figure 2).

The tuberous roots of yacon at $70-80 \%$ of dry matter is composed of fructo-oligosaccharides (FOS), among which over $60 \%$ (on dry basis) are inulin type $\beta(2 \rightarrow 1)$ fructans, mainly oligomers [8]. It has recently been hypothesized, in in vitro studies, that fructans have ROS scavenging capability 
and it was confirmed the significant antioxidant activity of inulin. Antioxidant capability of inulin is much higher than that of fructose, glucose and sucrose, which all are constituents of fructans $[18,35,36,37]$.

The increase of SOD activity could also be connected with the presence of the fructo-oligosaccharides in the root tubers of yacon. The effects of inulin-type fructans, such as FOS and inulin, on the intestinal absorption of minerals were established earlier. The acidification of intestinal contents by short-chain fatty acid producted by bacterial microflora of inulin-type fructans fermentation increases mineral solubility and absorbability. Furthermore, dietary inulin-type fructans seem to affect mineral absorption in large intestine by altering the permeability of tight junctions and the gene expression of mineral transporters such as calbindin-D9k (for $\mathrm{Ca}$ ), divalent metal transporter (DMT-1) (for $\mathrm{Fe}$ ) and zinc transporter 1 (ZnT1) (for Zn), supporting an effect of both paracellular and transcellular absorption [38]. Nevertheless, the number of studies concerning the bioavailability of trace elements $(\mathrm{Fe}, \mathrm{Cu}$ and $\mathrm{Zn})$ is proportionally lower, and these studies have thus far yielded contradictory results, but it has shown a significantly enhanced absorption of copper by FOS [39]. One of the reasons of copper-dependent metalloenzyme SOD activity reduction can be loss of $\mathrm{Cu}^{2+}$, a cofactor essencial for normal activity [4]. It can be assumed that the ability of FOS to enhance the absorption of copper can reduce the deficiency of this element under the conditions of diabetes and as a result may be one of the reason for increased SOD activity in animals with diabetes that were treated with yacon root tuber extract and suspension.

Similar to the leaves, yacon root tubers contain a number of phenolic compounds, among which there are novel caffeic acid esters of altraric acid: 2,4- or 3,5-dicaffeoylaltraric acid, 2,5-dicaffeoylaltraric acid, and 2,3,5- or 2,4,5-tricaffeoylaltraric acid, chlorogenic and ferulic acid, which have a pronounced antioxidant effect $[18,30,37,40]$.

It has been proved that yacon roots contain tryptophan, an antioxidant compound that scavenged hydroxyl radicals [41]. An essential amino acid L-tryptophan reacts with phenolic aldehydes and forms phenolic tetrahydrob-carboline alkaloids that effectively scavenges 2,2-azinobis(3-ethylbenzothiazoline)-6-sulfonic acid, which is frequently used to measure the antioxidant capacities of food [42].

Pronounced effect of leaves and root tubers water extracts of yacon and yacon root tubers powder aqueous suspensions on the state of prooxidant-antioxidant balance of red blood cells under the experimental diabetes mellitus type 1 may be caused by the synergistic action of biologically active substances with antioxidant action.

\section{Conclusions}

In conclusion, the present study demonstrates that water extracts of leaves and root tubers of yacon and yacon root tubers powder aqueous suspensions have significant antioxidant effect, which was proved by the decrease of TBARS and PCC and increase in SOD, CAT and GPx activity. The water extract of yacon root tubers at a dose of $500 \mathrm{mg} / \mathrm{kg}$ and aqueous suspension of root tubers powder stabilized by biocomplex PS possess the most pronounced antioxidant effect. These results may predetermine yacon as an active component in dietary supplements for the prevention of chronic diseases involving oxidative stress, among which diabetes mellitus is present.

\section{REFERENCES}

[1] A. A. Ghamdi, G. Badr, W. N. Hozzein, A. Allam, N. S. Al-Waili, M. A. Al-Wadaan, O. Garraud and A. Ghamdi, "Oral supplementation of diabetic mice with propolis restores the proliferation capacity and chemotaxis of $\mathrm{B}$ and $\mathrm{T}$ lymphocytes towards CCL 21 and CXCL12 by modulating the lipid profile, the pro-inflammatory cytokine levels and oxidative stress," BMC Immunology, vol. 16, no. 54, pp. 1$14,2015$.

[2] C. Phaniendra, D.B. Jestadi and L. Periyasamy, "Free radicals: Properties, sources, targets, and their implication in various diseases," Ind. J. Clin. Biochem, vol. 30, pp. 11-26, 2015.

[3] J. W. Baynes, "Perspectives in diabetes role of oxidative stress in development of complications in diabetes," DIABETES, vol. 40, pp. 405-412, 1991.

[4] O. R. Ayepola, N. L. Brooks and O. O. Oguntibeju, "Kolaviron Improved Resistance to Oxidative Stress and Inflammation in the Blood (Erythrocyte, Serum, and Plasma) of Streptozotocin-Induced Diabetic Rats," Scientific World Journal, vol. 24, pp. 1-8, 2014.

[5] J. Viskupicova, D. Blaskovic, S. Galiniak, M. Soszyński, G. Bartosz, L. Horakova and I. Sadowska-Bartosz, "Effect of high glucose concentrations on human erythrocytes in vitro", Redox Biology, vol. 5, pp. 381-387, 2015.

[6] J. Mohamed, S. W.Shing, M. H. M. Idris, S. B. Budin and S. Zainalabidin, "The protective effect of aqueous extracts of roselle (Hibiscus sabdariffa L. UKMR-2) against red blood cell membrane oxidative stress in rats with streptozotocin-induced diabetes", CLINICS, vol. 68, no. 10, pp. 1358-1363, 2013.

[7] M. Brownlee, "Biochemistry and molecular cell biology of diabetic complications", Nature, vol. 414, pp. 813-820, 2001.

[8] J. Lachman, E.C. Fernandez and M. Orsak, "Yacon [Smallanthus sonchifolia (Poepp. et Endl.) H. Robinson] chemical composition and use - a review", J. Plant Soil Environ., vol. 49, no. 6, pp. 283-290, 2003.

[9] J. S. Park, J. S. Yang, B. Y. Hwang, B. K. Yoo and K. Han, "Hypoglycemic effect of yacon tuber extract and its constituent, chlorogenic acid, in streptozotocin-induced diabetic rats", Biomolecules \& Therapeutics, vol. 17, no. 3, pp. 259-262, 2009.

[10] S. Baroni, F.Suzuki-Kemmelmeier, S. M. Caparroz-Assef, R. 
K. N. Cuman, C. A. Bersani-Amado, "Effect of crude extracts of leaves of Smallanthus sonchifolius (yacon) on glycemia in diabetic rats", Brazilian Journal of Pharmaceutical Sciences, vol. 44, no. 3, pp. 521-530, 2008.

[11] D. Russo, P. Valentão, P. B. Andrade, E. C. Fernandez and L. Milella, "Evaluation of antioxidant, antidiabetic and anticholinesterase activities of Smallanthus sonchifolius landraces and correlation with their phytochemical profiles" Int. J. Mol. Sci., vol. 16, pp. 17696-17718, 2015.

[12] S. M. Honoré, S. B. Genta and S. S. Sánchez, "Smallanthus sonchifolius (Yacon) leaves: an emerging source of compounds for diabetes management", Journal of Research in Biology, vol. 5(A), pp. 21-42, 2015.

[13] S. Terada, K. Ito, A. Yoshimura, N. Noguchi and T. Ishida, "The constituents relate to anti-oxidative and alpha-glucosidase inhibitory activities in Yacon aerial part extract", Yakugaku Zasshi, vol. 126, no. 8, pp. 665-669, 2006.

[14] K. Valentová, A. Moncion, I. de Waziers and J. Ulrichová, "The effect of Smallanthus sonchifolius leaf extracts on rat hepatic metabolism", Cell Biology and Toxicology, vol. 20, no. 2, pp. 109-120, 2004.

[15] K. Valentova, L. Cvak, A. Muck, J. Ulrichova and V. Simanek, "Antioxidant activity of extracts from the leaves of Smallanthus sonchifolius", European Journal of Nutrition, vol. 42, no. 1, pp. 61-66, 2003.

[16] K. Valentová, F. Sersen and J. Ulrichova, "Radical scavenging and anti-lipoperoxidative activities of Smallanthus sonchifolius leaf extracts", Journal of Agricultural and Food Chemistry, vol. 53, no. 14, pp. 5577-5582, 2005.

[17] X. Yan, M. Suzuki, M. Ohnishi-Kameyama, Y. Sada, T. Nakanishi and T. Nagata, "Extraction and Identification of Antioxidants in the Roots of Yacon (Smallanthus sonchifolius)", J Agric Food Chem., vol. 47, no. 11, pp. 4711-4713, 1999.

[18] S. S. Hong, S. A. Lee, X. H. Han, M. H. Lee, J. S. Hwang, J. S. Park, K. Oh, K. Han, M. K. Lee, H. Lee, W. Kim, D. Lee, and B. Y. Hwang, "Melampolides from the leaves of Smallanthus sonchifolius and their inhibitory activity of lps-induced nitric oxide production", Chem Pharm Bull, vol. 56, no. 2, pp. 199202, 2008.

[19] O. H. Lowry, N. J. Rosebrough, A. L. Farr and R. J. "Randall, Protein measurement with the Folin phenol reagent", J. Biol. Chem., vol. 193, pp. 265-275, 1951.

[20] R. L. Levine, D. Garland, C.N. Oliver, A. Amici, I. Climent, A.-G. Lenz, B.W. Ahn, S. Shaltiel and E.R. Stadtman, "Determination of carbonyl content in oxidatively modified proteins", Methods in Enzymology, vol. 186, pp. 464-478, 1990.

[21] J. Stocks and T. L. Dormandy, "The autoxidation of human red cell lipid induced by hydrogen peroxide", Br J Haematol., vol. 20, no. 1, pp. 95-111, 1971

[22] S. Chevary, T. Andyal and Ya.Shtrenger, "Determination of antioxidant properties of blood and its diagnostic value in the elderly”, Lab. Delo, vol. 10, pp. 9-13, 1991.

[23] M. A. Korolyuk, L. I. Ivanova and I. G. Mayorova, "Method for determining the activity of catalase", Lab. Delo, vol. 1, pp. 16-18, 1988 .
[24] V. M. Moin "Simple and specific method for determining the activity of glutathione peroxidase in erythrocytes", Lab. Delo, vol. 12, pp. 124-126, 1986.

[25] A. Dalle-Donne, R. Rossi, D. Giustarini, A. Milzani and R. Colombo, "Protein carbonyl groups as biomarkers of oxidative stress", Clin Chim Acta, vol. 329, pp. 23-38, 2003.

[26] I. A. Mahmoud and A. K. A. Nor El-Din, "Glucose-6-phosphate dehydrogenase activity and protein oxidative modification in patients with type 2 diabetes mellitus" Journal of Biomarkers, vol. 2013, pp. 1-8, 2013.

[27] V. M. Bhor, N. Raghuram and S. Sivakami, "Oxidative damage and altered antioxidant enzyme activities in the small intestine of streptozotocin-induced diabetic rats", The International Journal of Biochemistry \& Cell Biology, vol. 36, pp. 89-97, 2004.

[28] S. Merzouk, A. Hichami, S. Madani, H. Merzouk, A. Y. Berrouiguet, J. Prost, K. Moutairou, N. Chabane-Sari and N. A. Khan, "Antioxidant status and levels of different vitamins determined by high performance liquid chromatography in diabetic subjects with multiple complications", Gen. Physiol. Biophys., vol. 22, pp. 15-27, 2003.

[29] S. Baroni, J.F. Comar, F.S. Kemmelmeier, M. Shigueaki Mito, J. Oliveira de Melo, A. da Rocha and C. A. Bersani-Amado, "Beneficial effects of an hydroethanolic extract of Smallanthus sonchifolius leaves on the metabolic changes in diabetic rats", International Journal of Pharma and Bio Sciences, vol. 5, no. 3, pp. 183-196, 2014.

[30] J. Lachman, B. Havrland, A. Hejtmankova, E. C. Fernandez and V. Pivecl, "Content of polyphenolic antioxidants and phenolic acids in selected parts of yacon [Smallanthus sonchifolius (Poepp. et Endl.) H. Robinson], Scientia agriculturae bohemica, vol. 36, no. 2, pp. 49-54, 2005.

[31] D. Russo, N. Malafronte, D. Frescura, G. Imbrenda, I. Faraone, L. Milella, E. Fernandez and N..De Tommasi, "Antioxidant activities and quali-quantitative analysis of different Smallanthus sonchifolius [(Poepp. and Endl.) H. Robinson] landrace extracts", Natural Product of Research, vol. 23, pp. $1-5,2014$.

[32] Y. Kono, K. Kobayashi, S. Tagawa, K. Adachi, A. Ueda, Y. Sawa and H. Shibata, "Antioxidant activity of polyphenolics in diets rate constants of reactions of chlorogenic acid and caffeic acid with reactive species of oxygen and nitrogen", Biochimica et Biophysica Acta, vol. 1335, pp. 335-342, 1997.

[33] E.Aguilar and P. Bonilla "Antioxidant activity and immunological of flavonoids isolated from leaves of Smallanthus sonchifolius (yacon)", Ciencia e Investigación, vol. 12 , no. 1, pp. 15-23, 2009.

[34] M.S. Brewer, "Natural antioxidants: sources, compounds, mechanisms of action, and potential applications", Comprehensive Reviews in Food Science and Food Safety, vol. 10, pp. 221-247, 2011.

[35] V. Pasqualetti, A. Altomare, M.P.L. Guarino, V. Locato, S. Cocca, S. Cimini, R. Palma, R. Alloni, L. De Gara and M. Cicala, "Antioxidant Activity of Inulin and Its Role in the Prevention of Human Colonic Muscle Cell Impairment Induced by Lipopolysaccharide Mucosal Exposure", PLoS ONE, vol. 9, no. 5, pp. 1-9, 2014.

[36] E. Żary-Sikorska and J. Juśkiewicz "Effect of fructans with different degrees of polymerization on bacterial enzymes 
activity, lipid profile and antioxidant status in rats", Pol. J. Food Nutr. Sci., vol. 58, no. 2, pp. 269-272, 2008.

[37] D. Camposa, I. Betalleluz-Pallardela, R. Chirinosa, A. Aguilar-Galveza, G. Norattob and R. Pedreschic, "Prebiotic effects of yacon (Smallanthus sonchifolius Poepp. \& Endl), a source of fructooligosaccharides and phenolic compounds with antioxidant activity", Food Chemistry, vol. 135, no. 3, pp. 1592-1599, 2012.

[38] I. R. Lobo, E. H. S. Gaievski, E. De Carli, E. P. Alvares and C.Colli, "Fructo-oligosaccharides and iron bioavailability in anaemic rats: the effects on iron species distribution, ferroportin-1 expression, crypt bifurcation and crypt cell proliferation in the caecum", British journal of nutrition, vol. 112, no. 8, pp. 1286-1295, 2014.

[39] V. Ducros, J. Arnaud, M. Tahiri, C. Coudray, F. Bornet, C. Bouteloup-Demange, F. Brouns, Y. Rayssiguier, A.M.
Roussel, "Influence of short-chain fructo-oligosaccharides (sc-FOS) on absorption of $\mathrm{Cu}, \mathrm{Zn}$, and $\mathrm{Se}$ in healthy postmenopausal women", J Am Coll Nutr., vol. 24, no. 1, pp. 30-37, 2005.

[40] M. Takenaka, X. Yan, H. Ono, M. Yoshida, T. Nagata, T. Nakanishi, "Caffeic acid derivatives in the roots of yacon (Smallanthus sonchifolius)", J Agric Food Chem., vol. 51, no. 3, pp. 793-796, 2003.

[41] I. Castro, M. Caballero, A. Herbas and S. Carballo, "Antioxidants in yacon products and effect of long term storage", Ciênc. Tecnol. Aliment., Campinas, vol. 32, no. 3, pp. 432-435, 2012.

[42] T.Herraiz, J. Galisteo, C. Chamorro, "L-Tryptophan reacts with naturally occurring and food-occurring phenolic aldehydes: activity as antioxidants and free radical scavengers", Journal of Agricultural and Food Chemistry, vol. 51, pp. 2168-2173, 2003. 